\title{
Impact of blast design parameters on rock fragmentation in building stone quarries
}

\author{
Abhishek Sharma ${ }^{1, *}$, A. K. Mishra ${ }^{1}$, B. S. Choudhary ${ }^{1}$ and Rohit Meena \\ ${ }^{1}$ Indian Institute of Technology (Indian School of Mines), Dhanbad 826 004, India \\ ${ }^{2}$ Bakhrija Plot 4, Masonary Stone Mine, Gradient Business Consulting Private Limited, Narnaul 123 023, India
}

\begin{abstract}
Crushed stone aggregates are indispensable construction material which is produced by crushing of raw stone boulders raised from stone quarries through the process of drilling and blasting. Proper size of boulders fed to the crusher is important to eliminate congestion in the crushing circuit and obtaining the desired productivity. Drill-blast design parameters have a considerable effect on the degree of post-blast fragmentation. Bench height, spacing, burden, stemming, bench stiffness ratio and powder factor are controllable blast design parameters which considerably influence the fragmentation. By controlling these design parameters, optimum fragmentation can be achieved. Extensive field trials followed by scientific analysis have been done in this study which reveals the relation between drill-blast design parameters and post-blast fragmentation. Burden, spacing, stemming, bench stiffness ratio and powder factor were varied over a range of $30-45 \%$ which in turn caused distinctions in the mean fragment size in the range of $50-200 \%$ approximately. For optimum mean fragment size, the burden was found to be 21 times the blast hole diameter. Spacing dimension of 1.3 times the burden produced the optimum mean fragment size. Stemming length of 0.91 times of burden generated the optimum fragmentation. Mean fragment size was most optimum at powder factor of $1.02 \mathrm{~kg} / \mathrm{cum}$.
\end{abstract}

Keywords: Burden, drill-blast design parameters, fragmentation, spacing, stemming, stone quarries.

INFRASTRUCTURE is a country's bedrock of economic, social and human development. Globally, infrastructure is the key differentiator for a country's investment attractiveness, productivity, sustained and rapid growth, levels of poverty, human indices, capacity to deal with emergencies or disasters, resilience and confidence ${ }^{1}$. A country's physical infrastructure covers roads and highways, airports, railways, bridges, dams, power plants, metro rail and monorail systems, urban mass rapid transit systems, defense bases, institutional, commercial and residential buildings and factories ${ }^{2}$. Development of physical infrastructure in India not only contributes approximately $10 \%$ to its gross domestic product but also accounts for more

*For correspondence. (e-mail: abhishekmbm@rediffmail.com) than $65 \%$ of the country's total capital formation ${ }^{3}$. Manufactured stone aggregates are essential raw material for any construction mix and the country's consumption of stone aggregates is expected to reach a colossal level of 2.5 billion metric tonnes by 2020 (ref. 3). Such a higher level of consumption of stone aggregates is a direct result of progressive investments in the development of physical infrastructure in India ${ }^{4,5}$.

Stone aggregates are manufactured by crushing of raw stone boulders which are produced in stone quarries. Most common sizes of stone aggregates used for construction purpose are below $4.75 \mathrm{~mm}$ (generally called as crushed sand), $4.75-12.5 \mathrm{~mm}$ (generally called as $10 \mathrm{~mm}$ size aggregates), $12.5-22.5 \mathrm{~mm}$ (generally called as $20 \mathrm{~mm}$ size aggregates) and $22.5-42.5 \mathrm{~mm}$ (generally called as $40 \mathrm{~mm}$ size aggregates). Special sized products like granular subbase $(0 \mathrm{~mm}$ to $53 \mathrm{~mm})$ and railway track ballasts $(20-65 \mathrm{~mm})$ are also produced for specific applications. As construction standards followed by the project developers and contractors require the stone products to qualify certain quality standards as regards its compressive strength, density, specific gravity, water absorption, crushing value, impact value, Los Angles abrasion value and stripping value, to name a few, most of the stone deposits in the country used for construction purpose bear hard rocks like granite, gneiss, gabbro, basalt, quartzite and sandstone $\mathrm{e}^{6,7}$.

Due to tough physical and mechanical properties of these rock masses, drilling and blasting, by far, remains the most economical and productive method of disintegration of rock from its mother strata. The conventional cycle of operation being followed consists of drilling of holes, charging of these holes with explosives and initiation accessories followed by blasting, loading of blasted rock of proper size into the transporting vehicle and despatch for further process of crushing. During crushing, raw stone boulders are converted into stone aggregates of suitable sizes in various stages with each stage having its specific reduction ratio. Massabki ${ }^{8}$ stated that large size of raw boulders fed into the crusher hopper results in frequent congestion in the crushing circuit lowers productivity of the crushing operations and requires additional financial and human efforts in secondary blasting or breaking of such oversized feed. Generally, in India, a stone crushing plant can accommodate raw stone boulders 
up to $500 \mathrm{~mm}$ size and hence, the size distribution of rock mass by the process of blasting plays an important role in deciding the economics of not only stone mining operations but also front-end beneficiation using a crushing system.

The extent to which rock is broken into small pieces by blasting is known as fragmentation ${ }^{9}$. The full spectrum of various sizes of fragments and a size band's proportion with respect to other size bands in a blasted muck are known as fragment size distribution. Fragmentation in a blast is the outcome of interactions between several static, dynamic and kinetic parameters of the material being blasted and detonation of explosives ${ }^{10}$. Prasad et al. ${ }^{11}$ stated that the factors influencing rock fragmentation can be classified as controllable and non-controllable parameters. Controllable parameters are blast design and geometry and encompass input parameters like burden, spacing, bench height, stemming length, diameter of hole, delay sequence, explosive charge per delay, firing pattern, and powder factor. The uncontrollable parameters are largely geology-driven like rock mass properties, joints patters and joints spacing, which cannot be altered or modified ${ }^{12}$.

The degree of fragmentation plays an important role in optimizing the overall production cost including loading, hauling and crushing ${ }^{13}$. Choudhary ${ }^{14}$ studied and stated that if rock fragmentation is not controlled, it can increase production cost and delay the quarrying process due to unnecessary secondary blasting or sizing. The controllable factors like drill-and-blast design parameters have a great say in optimizing the fragmentation ${ }^{14}$. Brunton et al. ${ }^{15}$ demonstrated that proper fragmentation reduces the digging time of loading equipment and thus, the load and haul productivity increases. Therefore, blast design remains an area which can be experimented and studied in order to achieve optimum fragmentation and economy of operations - both drill-and-blast and subsequent cycle of activities like segregation, loading, hauling and crushing.

Many studies have taken place in the past to establish and explain the influence of drill-blast design parameters on blast fragmentation in many rocks and minerals like coal, limestone, metallic ores, etc. Stone quarries in Indian context suggest very different operational experience due to numerous factors, i.e. small area under mining lease, lower bench height, vicinity to residential and other structures, higher degree of segregation of oversized boulders required after blasting, and heterogeneous geology, to name a few. The present study attempts to establish how blast design in Indian building stone quarries influences blast fragmentation in terms of mean fragment size.

\section{Description of field work}

Field experiments were conducted at two different quarries of building stones situated in Bakhrija village of Mahendragarh district in the Indian state of Haryana.
These quarries are located adjacent to each other and are spread over dimensions of $1600 \mathrm{~m}$ in NS direction and $1100 \mathrm{~m}$ in EW direction with some buffer area falling in between. These quarries are known as Bakhrija Mining plots 2 and 4 respectively, and have sanctioned mining lease areas of 21.65 ha and 34.64 ha respectively.

Petrographic investigation shows that the rock mass contains $70-75 \%$ quartz, 20-25\% feldspar, 1-2\% mica and $2 \%-3 \%$ iron oxide. Key geo-mechanical properties of the rock mass (black quartzite) are furnished in Table 1.

A total of 30 blasts were included in the study that spanned a period of 7 months from January to July 2017. Variations were produced in key blast design parameters namely burden, spacing and stemming which in turn affected other indirect parameters like bench stiffness ratio and powder factor. Due attention was paid to the fact while varying one factor, the other two factors were kept constant. For the first ten blasts, bench height, spacing and stemming length were kept constant and the burden was varied to observe the variation in mean fragment size. For the next ten blasts, burden and stemming were pegged and the spacing was changed systematically and the mean fragment size measured. In the next ten blasts, both burden and spacing were pegged and variations were created in stemming length. Type of drilling machine, drill angle, type and make of explosives and accessories, and initiation patterns/firing sequence were kept constant throughout the study period. Drilling was done with pneumatically driven machines with a finished hole diameter of $110 \mathrm{~mm}$ with drill hole angle kept completely vertical. Holes were charged with class 2 cartridged slurry high explosives as primer charge (20-25\%) and class 2 cartridged slurry low explosives as columns charge (75-80\%). Engineering properties of explosives as provided by the explosives' manufacturer used are given Table 2.

Initiation was through a combination of instantaneous electric detonator and non-electric down the hole delay detonator of 450 milliseconds (ms) in-built delay. Surface connection was done using non-electric trunk line delay detonators of $17 \mathrm{~ms}, 25 \mathrm{~ms}$ and $42 \mathrm{~ms}$ in-built delays.

Blast holes were arranged in a square pattern and $\mathrm{V}$ or skewed $\mathrm{V}$ type of initiation sequence was followed throughout the study period.

Post blasting, images of muck pile from various angle were captured using a high resolution still camera. Considering the maximum boulder size of $500 \mathrm{~mm}$ which an average crushing plant can accommodate, a scale of $500 \mathrm{~mm}$ was set as reference and the same was used in subsequent image analysis. Images were captured periodically for any given muck pile to get a full pictorial representation of blast fragmentation. Due attention was paid to the recommendations made by researchers as regards blast image analysis for fragmentation assessment ${ }^{16,17}$. The captured images were analysed by Fragalyst ${ }^{\mathrm{TM}}$, a commercial, state-of-art image analysis software and 
Table 1. Key geo-mechanical properties of rock mas in quarries under study

\begin{tabular}{lll}
\hline Physical/mechanical property & Observed value & \multicolumn{1}{c}{ Test protocol } \\
\hline Specific gravity & $2.79 \mathrm{~g} / \mathrm{cc}$ & IS:2386 (Part III)-1963-2011 \\
Water absorption & $0.2 \mathrm{w} / \mathrm{w} \%$ & IS:2386 (Part III)-1963-2011 \\
Aggregates impact value & $16 \%$ & IS:2386 (Part IV)-1963-2011 \\
Aggregates crushing value & $19 \%$ & IS:2386 (Part IV)-1963-2011 \\
Los Angles abrasion value & $25 \%$ & IS:2386 (Part IV)-1963-2011 \\
Stripping value & $96 \%$ & IS:6241-2008 \\
$10 \%$ Fines value & 24 tonnes & IS:2386 (Part IV)-1963-2011 \\
\hline
\end{tabular}

Table 2. Engineering properties of explosives and accessories used during the study

\begin{tabular}{lcc}
\hline & \multicolumn{2}{c}{ Description } \\
\cline { 2 - 3 } Property & Primer charge & Column charge \\
\hline Weight and diameter of cartridge & $2.78 \mathrm{~kg}, 83 \mathrm{~mm}$ & $2.78 \mathrm{~kg}, 83 \mathrm{~mm}$ \\
Nominal density & $1.18-1.25 \mathrm{~g} / \mathrm{cc}$ & $1.18-1.25 \mathrm{~g} / \mathrm{cc}$ \\
Relative weight strength & $85-130 \%$ & $75-92 \%$ \\
Relative bulk strength (ANFO @ $0.80 \mathrm{~g} / \mathrm{cc})$ & $109-184 \%$ & $98-130 \%$ \\
Velocity of detonation (VoD) & $3500 \mathrm{~m} / \mathrm{s}$ & $3500 \mathrm{~m} / \mathrm{s}$ \\
\hline
\end{tabular}

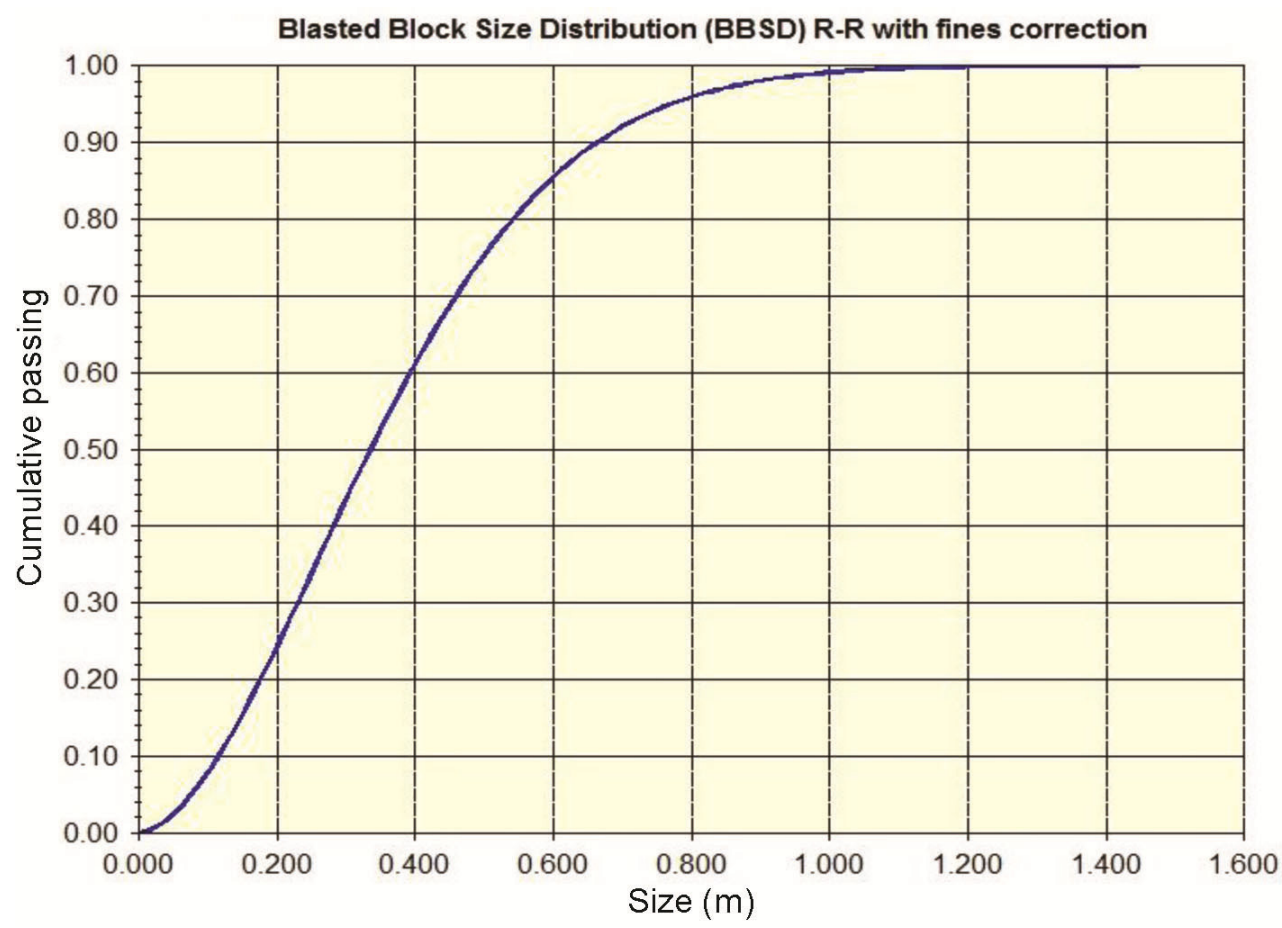

Figure 1. Fragalyst ${ }^{\mathrm{TM}}$ analysed Rosin-Rammler distribution curve.

a Rosin-Rammler distribution curve was obtained (Figure 1).

\section{Field experiments - analysis and result}

Fragmentation output processed by Fragalyst ${ }^{\mathrm{TM}}$ is generated in various sizes, however, dmean fragment size (K50), the size at which $50 \%$ of the fragments in the blasted muck pile pass cumulatively, was considered for evaluation of blast results. The data set including blast design inputs and post-blast fragment size obtained from Fragalyst $^{\mathrm{TM}}$ aided Rosin-Rammler distribution are shown in Table 3.

Graphical analysis and its interpretation on finding a relationship between various drill-blast design parameters and fragmentation are detailed below. 


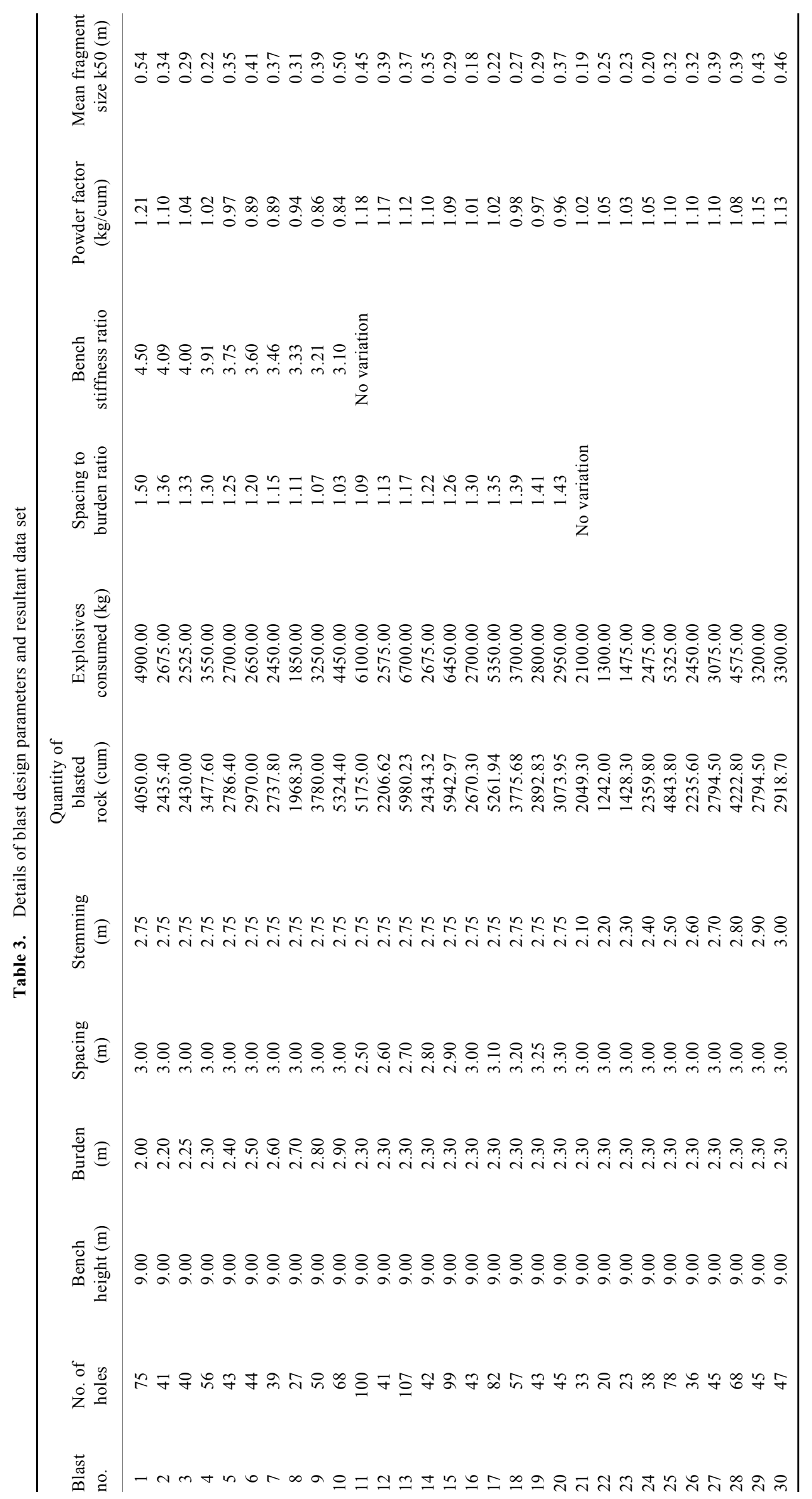


Burden versus mean fragments size-the burden was varied from $2 \mathrm{~m}$ to $2.9 \mathrm{~m}$, keeping spacing and stemming constant at $3 \mathrm{~m}$ and $2.75 \mathrm{~m}$ respectively, in the first 10 blasts. Mean fragment size exhibited a positively proportionate relation with burden, i.e. mean fragment size increased with increase in burden. The finest fragment size was achieved at the burden value of 21 times the blast hole diameter. The relation obtained is furnished in Figure 2.

When the burden was increased, the thickness of burden rock mass beam also got amplified and the explosion energy found enhanced resistance to effectively fracture and displace the rock, which escalated the concentration of coarser particles in the post-blast muck profile and hence, the resultant mean particle size increased progressively. An increment in burden also reduced the ejection velocity of the muck pile and the quantum of displacement of rock mass along horizontal and vertical dimensions which caused less availability of scope for in-trajectory collision and resulted in coarser fragmentation.

Spacing versus mean fragments size-for the next 10 blasts, the burden was fixed at $2.30 \mathrm{~m}$ and spacing was varied. Stemming length was also kept unchanged at $2.75 \mathrm{~m}$. As shown in Figure 3, the mean fragment size decreased with increase in spacing from 2.50 to $3.00 \mathrm{~m}$ and increased thereafter as spacing was increased up to $3 \mathrm{~m}$. The smallest fragment size was obtained at a spacing value of 1.3 times the burden.

Very small values of spacing caused excessive crushing between the charges and superficial crater breakage

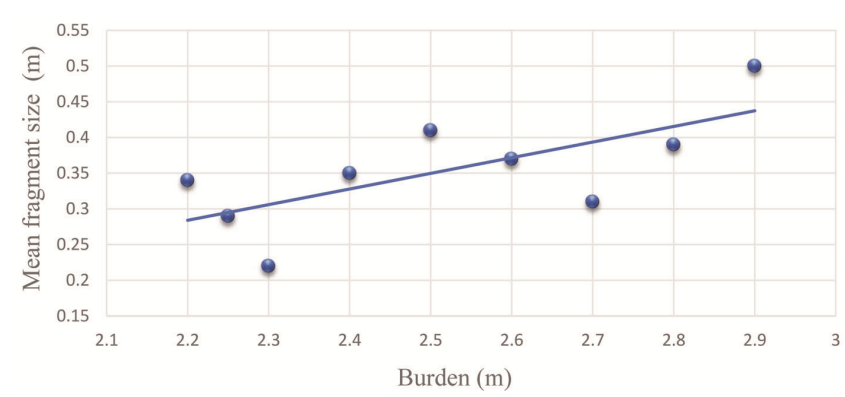

Figure 2. Relation between burden and mean fragment size.

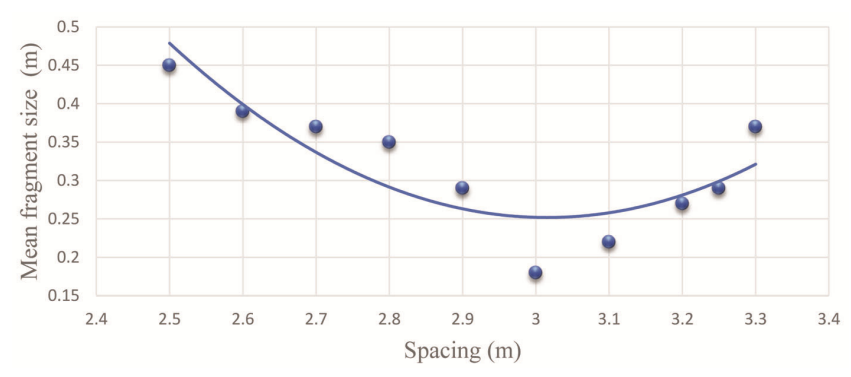

Figure 3. Relation between spacing and mean fragment size. resulting in coarser fragmentation in front of the blast holes. As spacing was increased to a certain limit for a fixed burden distance, explosives energy was utilized in creating radial fractures and adequate breakage resulting in finer mean fragment size. Effective breakage and adequate fracturing decreased with further increase in spacing beyond an optimum level as the availability of explosion energy per unit of area under breakage decreased.

Spacing to burden ratio versus mean fragments size - as shown in Figure 4, when spacing to burden ratio was increased from 1.0 to 1.3 , the mean fragment sizes were found reducing. Mean fragment size increased further when spacing to burden ratio was enhanced to 1.50 .

The relation can be explained as increased spacing-toburden ratio to a certain extent created thin ledges of rock mass which finally broke into smaller fragments. Increasing spacing-to-burden ratio further hampered propagation of radial cracks and this resulted in coarser fragmentation.

Stemming length versus mean fragment size - in the last 10 blasts, spacing length was varied keeping burden and spacing pegged at 2.3 and $3 \mathrm{~m}$ respectively. Stemming height was also found to affect fragmentation in a positively proportionate relation as shown in Figure 5. Finest fragment size was obtained at stemming value equivalent to 0.91 times the burden.

Increase in stemming length enhanced the height of the uncharged portion of the blast hole which increased the

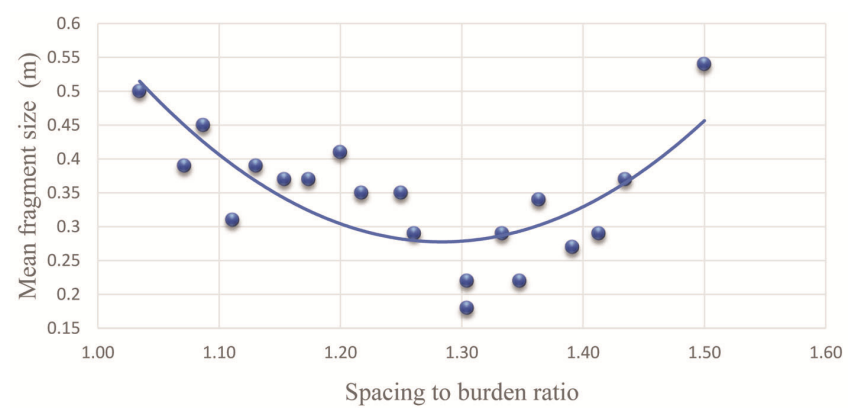

Figure 4. Relation between spacing to burden ratio and mean fragment size.

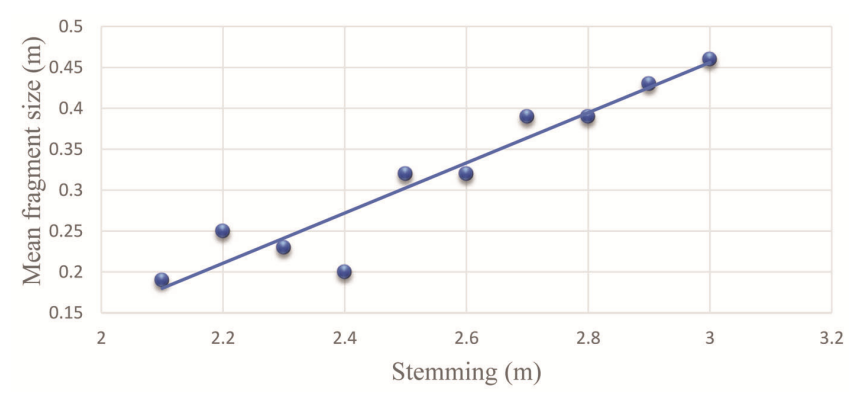

Figure 5. Relation between stemming length and mean fragment size. 
Table 4. Summary of changes in input parameters and its influence on resultant mean fragment size

\begin{tabular}{|c|c|c|c|c|c|c|}
\hline \multirow[b]{2}{*}{ Parameters varied } & \multirow{2}{*}{$\begin{array}{l}\text { Base } \\
\text { value }\end{array}$} & \multirow{2}{*}{$\begin{array}{c}\text { Maximum } \\
\text { varied value }\end{array}$} & \multirow{2}{*}{$\begin{array}{c}\text { Range of } \\
\text { variation } \\
(\%)\end{array}$} & \multirow[b]{2}{*}{ Trend of relation } & \multicolumn{2}{|c|}{ Change in mean fragment size $\mathrm{k} 5 \mathrm{C}$} \\
\hline & & & & & Range (m) & Percentage \\
\hline Burden (m) & 2.00 & 2.90 & 45 & Linear, directly proportionate & 0.54 to 0.22 & 59 \\
\hline Spacing $(\mathrm{m})$ & 2.50 & 3.30 & 32 & $\begin{array}{l}\text { Downward exponential, decrease till spacing } \\
\text { to burden ratio of } 1.3 \text {, increase thereafter }\end{array}$ & 0.45 to 0.18 & 60 \\
\hline $\begin{array}{l}\text { Spacing to } \\
\text { burden ratio }\end{array}$ & 1.03 & 1.50 & 46 & $\begin{array}{l}\text { Downward exponential, decrease till spacing to } \\
\text { burden ratio of } 1.3 \text {, increase thereafter }\end{array}$ & 0.54 to 0.18 & 67 \\
\hline Stemming $(\mathrm{m})$ & 2.10 & 3.00 & 43 & Linear, directly proportionate & 0.19 to 0.46 & 142 \\
\hline Bench stiffness ratio & 4.50 & 3.10 & 31 & Linear, inversely proportionate & 0.54 to 0.22 & 59 \\
\hline $\begin{array}{l}\text { Powder factor } \\
\qquad(\mathrm{kg} / \mathrm{cum})\end{array}$ & 0.84 & 1.21 & 45 & $\begin{array}{l}\text { Downward exponential, decrease till powder } \\
\text { factor of } 1.02 \mathrm{~kg} / \mathrm{cum} \text {, increase thereafter }\end{array}$ & 0.18 to 0.54 & 200 \\
\hline
\end{tabular}

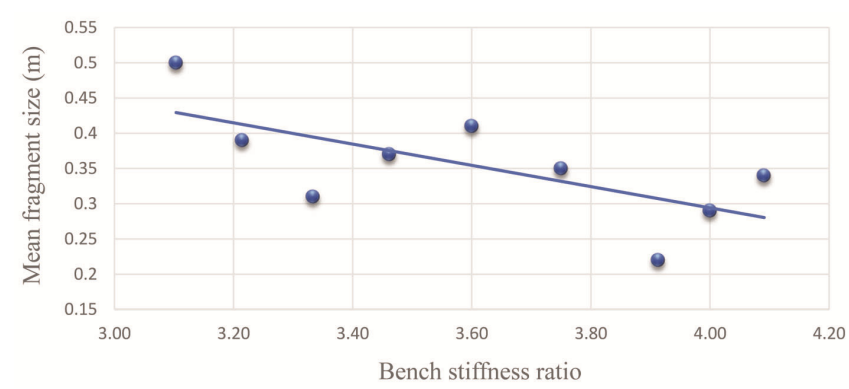

Figure 6. Relation between bench stiffness ratio and mean fragment size.

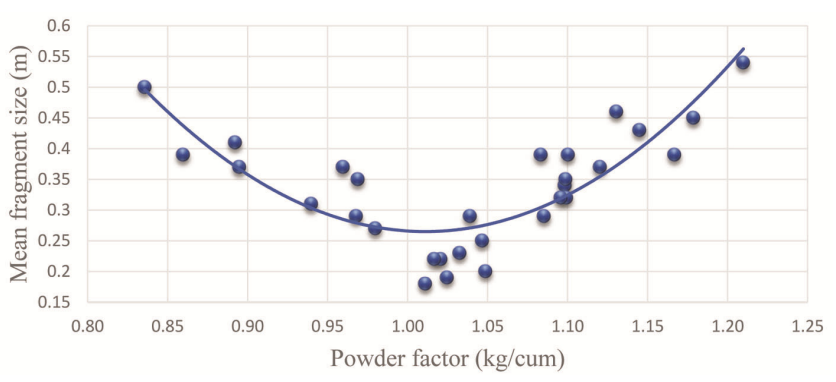

Figure 7. Relation between powder factor and mean fragment size.

generation of coarse fragments, especially in the collar region. Also, when multi-row blast was conducted, increased stemming length caused congested relief which generated coarser fragments.

Bench stiffness ratio versus mean fragment size-as bench height was kept constant at $9 \mathrm{~m}$, change in burden values caused changes in bench stiffness ratio. Mean fragment size exhibited reduction with increase in bench stiffness ratio. The trend is displayed in Figure 6.

With increase in bench stiffness ratio, the burden rock mass beam under flexion became more flexible and less stiff and made the rock mass easier to get deformed and displaced generating fines fragments.
Effect of powder factor on mean fragment size-mean fragment size decreased when powder factor was moved from $0.84 \mathrm{~kg} / \mathrm{cum}$ (cubic metres) to $1.02 \mathrm{~kg} / \mathrm{cum}$ and increased with further increment in the powder factor. The relation is exhibited in Figure 7.

The relation between powder factor and mean fragment size can be explained as the actual requirement of explosives energy to create effective fragmentation and cause displacement of rock mass kept increasing till a powder factor of $1.02 \mathrm{~kg} /$ cum was achieved. However, increasing availability of explosives energy did not mean its increased utilization. Increasing powder factor beyond the optimum caused untoward post-blast effects like early ejection of stemming column, over-breaks, air blasts, etc. which left less explosion energy to cause actual fracturing and movement of rock mass, resulting in coarser mean fragment size.

\section{Range of change in mean fragment size with variation in blast design parameters}

Range and percentage of change in output, i.e. mean fragment size as a result of variations in input blast design parameters are exhibited in Table 4.

\section{Conclusion}

(a) Drill-blast design parameters affect blast fragmentation which, in turn, influences subsequent cycle of operations, i.e. secondary sizing of oversized boulders, loading, efficiency of transporting vehicle and crushing. Attainment of optimum fragmentation is key to productivity and profitability of quarrying operations.

(b) Key blast design parameters, i.e. burden, spacing and stemming, when moved systematically and analysed, it was observed that measurable and verifiable variations were caused in the mean fragment size. Each of these parameters affected the mean fragment size in a distinguished manner. 
(c) Mean fragment size exhibited linear relation with burden. For the bench height of $9 \mathrm{~m}, 45 \%$ increment in burden caused mean fragment size to increase in range $59 \%$ approximately.

(d) Mean fragment size moved in quadratic relation with spacing. Increment in spacing by $32 \%$ caused mean fragment size to vary in the range of $60 \%$. A similar trend was obtained in relation between spacing-to-burden ratio and mean fragment size where $46 \%$ variation in spacingto-burden ratio caused mean fragment size to vary by $67 \%$.

(e) Mean fragment size moved in a directly proportionate manner with stemming length. An incremental variation by $46 \%$ in stemming length caused mean fragment size vary by $140 \%$ approximately.

(f) Mean fragment size displayed inversely proportionate relation with the bench stiffness ratio. Mean fragment size decreased by $59 \%$ approximately as bench stiffness ratio was increased by $31 \%$.

(g) Mean fragment size exhibited quadratic relation with the powder factor. As powder factor was varied over a range of $45 \%$, mean fragment size witnessed variation in a range of $200 \%$.

1. Kumar, D., Vivekananda International Foundation, Development of Infrastructure in India - The Vehicle for Developing Indian Economy, 2017.

2. Ananthamurthy, B. S. and Sharma, A., Mining for sustainable growth of Indian construction industry. In Proceedings of Golden Jubilee Seminar on Mining Technology for Sustainable Development - MineTech'11, 2011, pp. 29-139.

3. Venkataramaman, R., Nagendran, V. and Sharma, A., Crushing of aggregates with fixed shaft cone crusher: a green initiative by L\&T. In Proceedings of Geominetech Symposium, 2013, pp. 5963.

4. Planning Commission, Government of India, India's 12th Five Year Plan 2012-17, Parts I \& II, 2013.

5. Ministry of Finance, India's Union Budget for Financial Year 2017-18, 2017.

6. Bureau of Indian Standards, Specifications for Coarse and Fine Aggregates from Natural Sources for Concrete, Indian Standards (IS), 383-1970, 1971.
7. Indian Road Congress on behalf of Government of India, Ministry of Road, Transport and Highways (MORTH) Specification for Road and Bridge Works, 1971, 5th revision.

8. Massabki, R. F., Reducing costs in quarring with optimized drilling and blasting design. In Proceedings of the 24th World Mining Congress, Rio de Janeiro, Brazil, 2016, pp. 208-212.

9. Rustan, A., Rock Blasting Terms and Symbols, A. A. Balkema, Rotterdam, Brookfield, 1998.

10. Sarathy, M. O., 'Powder factor'-based tenders - progressive or regressive? Mining Engineers J., 2017, 19(8), 15-24.

11. Prasad, S., Choudhary, B. S. and Mishra, A. K., Effect of blast design parameters on blast-induced rock fragmentation size $-\mathrm{a}$ case study. In International Conference on Deep Excavation, Energy Resources and Production, IIT Kharagpur, 2017, pp. 1-7.

12. Singh, P. K., Roy, M. P., Paswan, R. K., Sarim, Md., Kumar, S. and Jha, R. R., Rock fragmentation control in opencast blasting. J. Rock Mech. Geotech. Eng., 2016, 8, 225-237.

13. Jethro, M. A., Sheshu, S. A. and Kayode, T. S., Effect of fragmentation in loading at Obajana Cement Company, Nigeria. Int. J. Sci. Eng. Res., 2016, 7(4), 608-620.

14. Choudhary, B. S., Firing patterns and its effect in Muckpile shape parameters and fragmentation in quarry blasts. Int. J. Res. Eng. Technol., 2013, 2(9), 32-45.

15. Brunton, I., Thornton, D., Hodson, R. and Sprott, D., Impact of blast fragmentation on hydraulic excavator dig time. In Proceedings of Fifth Large Open Pit Mining Conference, Kalgoorlie, WA, 2003, pp. 39-48.

16. Maerz, N. H., Franklin, J. A., Rothenburg, L. and Coursen, D. L., Measurement of rock fragmentation by digital photo analysis. In Fifth International Congress, International Society for Rock Mechanics, 1987, pp. 687-692.

17. Sanchindria, J. A., Segarra, P. and Lopez, L. M., A practical procedure for the measurement of fragmentation by blasting by image analysis. Rock Mech. Rock Eng., 2005, 39(4), 359-382.

ACKNOWLEDGEMENTS. We thank the management of M/s Tirupati Viniyoge Private Limited, Kolkata and Gradient Business Consulting Private Limited, Kolkata where the studies were conducted, for their permission, help, support and co-operation. We also acknowledge the support and co-operation extended by the mining team and frontline supervisors of both the companies.

Received 25 May 2018; revised accepted 5 March 2019

doi: $10.18520 / \mathrm{cs} / \mathrm{v} 116 / \mathrm{i} 11 / 1861-1867$ 